\title{
Remote Laboratory Collaboration Plan in Communications Engineering
}

\author{
http://dx.doi.org/10.3991/ijoe.v8i4.2098
}

Akram A. Abu-aisheh and Tom E. Eppes

University of Hartford, West Harford, Connecticut, USA

\begin{abstract}
Communications laboratories for electrical engineering undergraduates typically require that students perform practical experiments and document findings as part of their knowledge and skills development. Laboratory experiments are usally designed to support and reinforce theories presented in the classroom and foster independent thinking; however, the capital cost of equipment needed to sustain a viable laboratory environment is large and ongoing maintenance is an annual expense. Consequently, there is a need to identify and validate more economic solutions for engineering laboratories. This paper presents a remote laboratory collaboration plan for use in an elctrical engineering communications course.
\end{abstract}

Index Terms-Remote, Virtual, E-learning environment, Communications Engineering

\section{INTRODUCTION}

Science and engineering courses typically involve students performing practical experiments and assignments in laboratories as part of their knowledge and skills development. This is essential in reinforcing theories learned in lectures and in providing means to foster independent thinking. Knowledge and skills development also bring the course theory alive so students can see how unexpected events and natural phenomena affect real-world measurements and control algorithms.

Equipping an upper-class electrical engineering laboratory, as in the case of communications Engineering labs, is a major expense and its maintenance is expensive and can be difficult. Highly qualified teaching assistants are required to set up the laboratory experiments, instruct in the laboratory, and grade the laboratory reports, and the laboratories are available only when equipment and teaching assistants are both available. So, resources limitation in the provision of laboratory hardware is a principal impediment that has been increasingly marginalizing the quality of engineering and engineering technology education [1].

The use of remote laboratories has been shown to help in overcoming the problem of limited available laboratory equipment. Another sometimes overlooked advantage is promoting collaboration between programs from different institutions. In such cases, high quality experiments can be made available to more students. In addition, access to expensive, one-of-a-kind test and measurement equipment can be shared by a larger pool of users. This paper presents a remote laboratory collaboration plan for an electrical engineering communications course that increases access and fosters collaboration while reducing cost.

\section{REMOTE AND VIRTUAL LABORATORIES AND DISTANCE LEARNING ENVIRONMENTS}

A growing body of work has appeared that has further validated both the technological viability of distance laboratories and their effectiveness in delivering a worthwhile laboratory experience. Limitations on equipment access and funding reduce the availability of laboratory resources in many institutions. Remote labs help alleviate this problem by increasing access and simultaneously reducing cost. References [2\&3] are examples of some of the early work in developing a remote lab capability.

Distance learning, also referred to as e-learning, can be used to help universities and technical colleges overcome the limitation of available resources in the provision of communications engineering laboratory hardware and infrastructure. One approach that can be implemented to overcome this problem is to expand e-learning activities in programs with limited resources to take advantage of remote control technology.

This paper presents a plan for cooperation and resource sharing among universities in teaching in the areas of RF Communications, Data Communications, and Fiber Optic Communications using remote laboratories. The laboratory section in these courses has typically required expensive equipment that is out of reach for many institutions.

The objective of this work is to present a plan for remote laboratory collaboration in engineering communications courses. This plan shows some strategies that can be followed and sample set-ups that can be used when implementing remote communications laboratories.

\section{REMOTE LABORATORIES COLLABORATION PLAN}

Sharing a remote laboratory platform between two institutions during the same timeframe requires detailed planning across several fronts. In our case, laboratory hardware is shared between onsite users at one institution with remote users at the other.

After some discussion, two main approaches were identified that allow as much flexibility as possible. Both approaches require a high degree of pre-planning of experiment details with minimal change during the semester. As given in Table I, the first approach called 'synchronous' presumes that both sites agree to assign the same experiments over the same timeframe. The advantage is that the set-up and take down for each experiment need only be performed once during a course. The main issue is how to avoid time conflicts between the two sets of users. This can be done by communicating available time blocks to each set of students and starting/stopping the LabVIEW remote VI browser. 
TABLE I.

APPROACHES TO COURSE COLLABORATION

\begin{tabular}{|l|l|l|}
\hline Approach & Advantage & Disadvantage \\
\hline $\begin{array}{l}\text { Synchro- } \\
\text { nous }\end{array}$ & $\begin{array}{l}\text { Minimal set up } \\
\text { and take down } \\
\text { required }\end{array}$ & $\begin{array}{l}\text { Experiments \& } \\
\text { timing must over- } \\
\text { lap }\end{array}$ \\
\hline $\begin{array}{l}\text { Asynchro- } \\
\text { nous }\end{array}$ & $\begin{array}{l}\text { Experiments \& } \\
\text { timing are flexi- } \\
\text { ble }\end{array}$ & $\begin{array}{l}\text { Resources needed } \\
\text { for frequent coor- } \\
\text { dination }\end{array}$ \\
\hline
\end{tabular}

The second approach called 'asynchronous' is the most flexible; however, it requires weekly coordination to ensure that the relevant experiments are ready to be performed especially for the remote users. Both require that an onsite technician be available in case there is a problem.

Another aspect that must be addressed is estimating how many remote students can be served by each ELVIS platform. Onsite users spend a predictable amount of time in the laboratory. The remainder can be devoted to the remote users. In our case, we started with 168 hours/week ( 7 days times 24 hours/day) and subtracted 10 hours for onsite use plus 5 hours for offline purposes. Thus, each lab station is available for 153 hours/week for remote users, and based on past experience, we estimate that one station can support 10 remote users. Assuming the average remote lab takes 4 hours to complete, the lab station utilization is $26 \%$. Keeping this figure low ensures that students will not likely experience a queue when trying to use the system remotely. It also allows for intermittent networking problems, local or in the internet core, which may reduce availability.

This paper builds on the authors' prior work [1] on using a DATEX trainer to perform RF and digital communications experiments that can also be made available in a distance learning environment. The first component in the proposed remote lab set-up is the National Instrument's Educational Remote Instrumentation Suite (NI ELVIS) [4]. The second component is Emona's FOTEX and DATEx trainers [5] that are designed as compatible plugin modules for the ELVIS II platform.

The FOTEx and DATEx trainers are plug-in modules for the ELVIS platform. This experimental set-ups enables students to perform hands-on experiments that re-enforce engineering communications concepts and do so remotely with LABVIEW. The FOTEx - ELVIS II-based remote laboratory set-up is shown in Figure 1 while the DATEx ELVIS II-based remote laboratory set-up is shown in Figure 2. Students log-in via the internet and access a virtual instrument panel for use in acquiring data. Both optical and RF communications experiments such as bandwidth-limited signals and frequency spectra may be completed by student without them being present in the laboratory.

There are several course management systems that may be used to extend delivery beyond the traditional face-toface classroom. Centra Systems (saba.com) and Blackboard (blaceboard.com) are used widely in the USA and Canada. Licensing costs, annual software maintenance fees, and lack of adequate IT support have limited utilization on a global scale. Based on open source technology, Moodle (moodle.org) is a popular alternative that has been

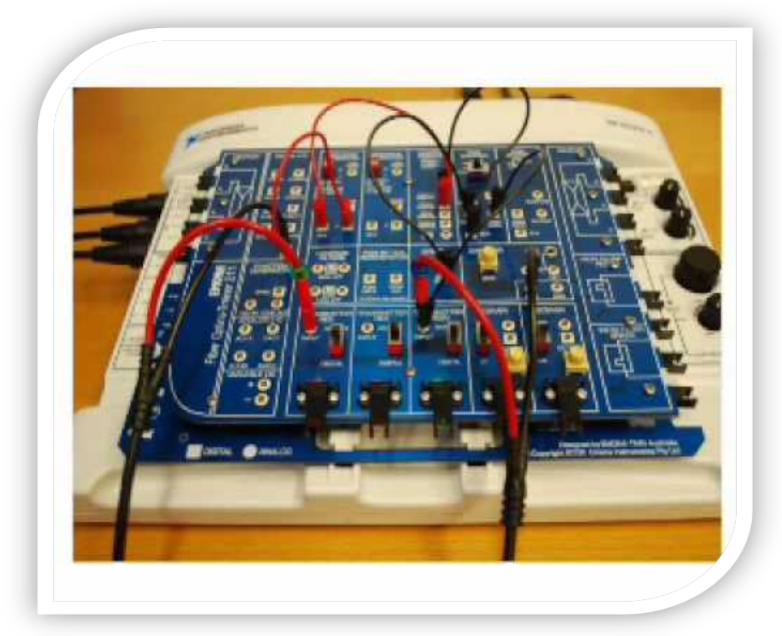

Figure 1. FOTEx-ELVIS II Communications Bundle.

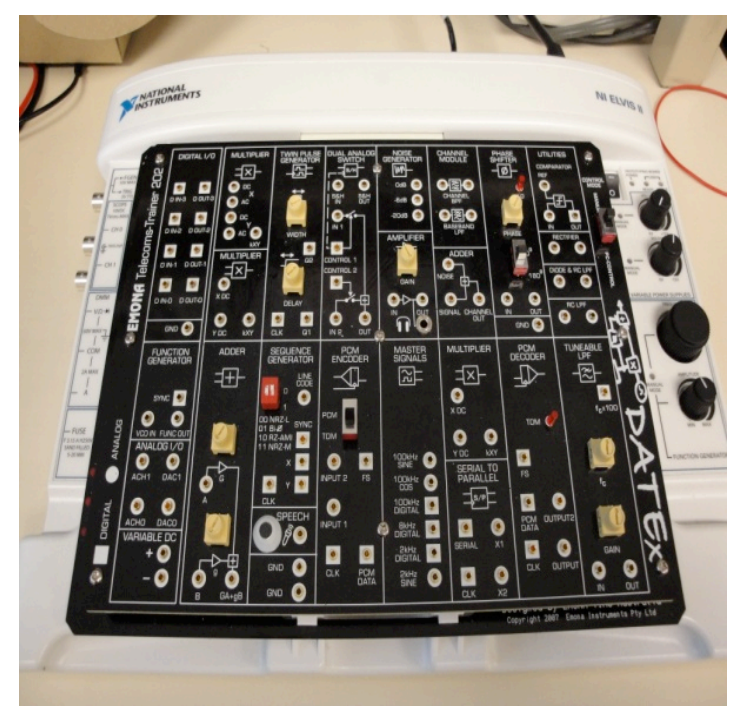

Figure 2. DATEx-ELVIS II Communications Bundle.

\section{COLLABORATION SOFTWARE PLATFORM}

adopted in the USA, Canada, Europe, and many other parts of the world. All of these systems provide the instructor and students a rich array of web-based features to publish course materials, submit completed work, provide feedback on grades and monitor access/participation levels. Such systems are an important element in delivering a remote laboratory course.

A set of laboratory workstations are an essential element in this laboratory collaboration effort. For each workstation, the authors have found LabVIEW to be an attractive option. A major advantage of LabVIEW is a built-in web server that provides a convenient way to publish virtual instrument panels to distant users. An instructor with limited IT support and networking knowledge, can setup remote panels for the FOTEx and DATEx communications trainers that contain one or more ELVIS II instruments. Once the LabVIEW remote VI browser at a workstation is activated, an instructor can insert a link along with experiment details into the course management system. For best results, static IP addresses should be used at each of the workstation computers. Once a student clicks on the link, an instrument panel opens. If the 


\section{SPECIAL FOCUS PAPER \\ REMOTE LABORATORY COLLABORATION PLAN IN COMMUNICATIONS ENGINEERING}

workstation is in use, a message appears and notifies the student of their position in the waiting queue.

There are two issues with the above approach. First, there is no lab workstation authentication required. Anyone with knowledge of a link can access the remote VI browser, and if public IP addresses are used, a hacker may attempt to break-in. Second, there is no simple way to manage a pool of multiple lab workstations that support the same experiment. Neither the course management system nor LabVIEW remote VI features multiple access; therefore, there is some scale of operation where an institution will need a lab management system. A lab management system acts as an intermediary so that many courses and instructors can be served. Several lab workstations can be made available to the students to avoid queuing. Another alternative is to use a reservation system where students select a day and time to perform an experiment.

Both communication setups presented here use LabVIEW, so there is a need for a platform that is designed using LabVIEW software. A major advantage of LabVIEW is that it provides a convenient way to setup a PC as a server and establish server/client environment. Hence, an instructor with limited IT support, and networking and programming knowledge, can easily setup LabVIEWbased laboratory modules as needed for the FOTEx and DATEx Communications Trainers-ELVIS II educational platforms.

Currently, there are no commercial or open source platforms for a lab management system. Several proprietary systems have been built, tested placed into service. One solution called the Integrated Virtual Learning Platform (IVLP) has been reported [6]. IVLP is entirely based on LabVIEW, providing a user-friendly and configurable remote access to laboratory experiments. Another platform known as Automated Laboratory Test Environment (ALTE) provides similar functionality [2]. While these platforms solve the problem of remote lab management, each requires ongoing maintenance. At some future point, a commercial and/or open source lab management module may be developed so a more supportable solution is available to all institutions.

\section{SAMPLE EXPEREMINT: USING THE EMONA FOTEX} WDM FILTER MODULES FOR OPTICAL SIGNAL FILTERING

The theory behind each optical fiber system allows many thousands of communication to take place over a specific network at once. In order to achieve this system, the time division multiplexing (TDM) is used in this experiment. TDM involves coupling different light sources to the fiver which operated at different wavelength. To get our point, the filters are needed to pick-out light at one wavelength and reject light at others. Two kind of WDM filter are used: The red LED and the green LED on the FOTEX board were used for this experiment. The red light passes relatively unaffected but attenuates light at other colors including green and the green light passes but attenuates the red light.

To give a feeling of the level of work involved in performing experiments using the FOTEx-ELVIS II set-up, we are presenting the steps followed to perform signal filtering.
1. Make sure the ELVIS II unit is turned off and connect the USB cable between the PC and the ELVIS II unit.

2. Connect the Enoma FOTEx board to the NI ELVIS board.

3. Turn on the power to the ELVISII unit and to the FOTEx board then launch the NI ELVISmx software on the computer. Note that the connection between the PC and the ELVIS board is performed through a USB cable connection. We wanted to note the importance of this interaction the fact that we can literally build the circuit in class and remotely manipulate it while sitting at home.

4. Set the Variable of the power supply positive output to $0 \mathrm{~V}$.

5. Set the Mode Control of one of the Red LED to Ana$\log$.

6. Connect the input of the Red Transmitter to the output function of the function generator. The optical fiber patch was faced to the table.

7. Observe the red light on the end of the fiber. It should be pulsing about one pulse/second.

8. Connected the optical fiber to the WDM filter red. We faced again the free end of the optical fiber to the desk; it was realized that the red light of the filter was pulsing about one pulse/second. Then, we replaced the red WDM Filter module for the green one by keeping up the same set up previously. We pointed the green WDM Filter to the desk; we noticed that the brightness was significantly lower than the one we saw with the red WDM Filter. The output is still visible at the output of WDM filter since it is not a ideal filter.

9. Increase the message frequency to $1 \mathrm{KHz}$. The Receiver module was selected and the Gain Control was set up to LO.

10. Turned the Variable Gain control all the way clockwise. Then, connect $\mathrm{Ch} 0$ and $\mathrm{Ch} 1$ to the output function of the function generator and to the output of the receiver, respectively. It was distinguished that the function generator was used to model an analog model. The red transmitter converts the message to light and transmits it along the fiber optic. The light is fibered and converted back to an electrical signal. The scope for Ch1 was observed and can be seen in the graph below.

11. Replace the red WDM Filter for the green WDM Filter and observe the Receiver new output. The WDM green filter filters the input signal i.e the green WDM filter module lets the green light pass but attenuates the red light.

12. Set the scope Ch1 Scale control set up to $20 \mathrm{mV} / \mathrm{div}$ instead of $1 \mathrm{~V} /$ div. A small test was used here to confirm that the signal is a copy of the message, by momentarily disconnecting one end of any one of the optical patch leads. The message can be recovered at the receiver if we use EDFA before the PIN detector.

Figures 3 and 4 show the monitoring of filtering an optical signal using the proposed test set-up. Figure 3 presents the input to the optical filter while figure 4 shows the optical output of the WDM filter. The scale in figure 4 was changed to show both signal on the same snapshot of the LabVIEW Oscilloscope VI. 


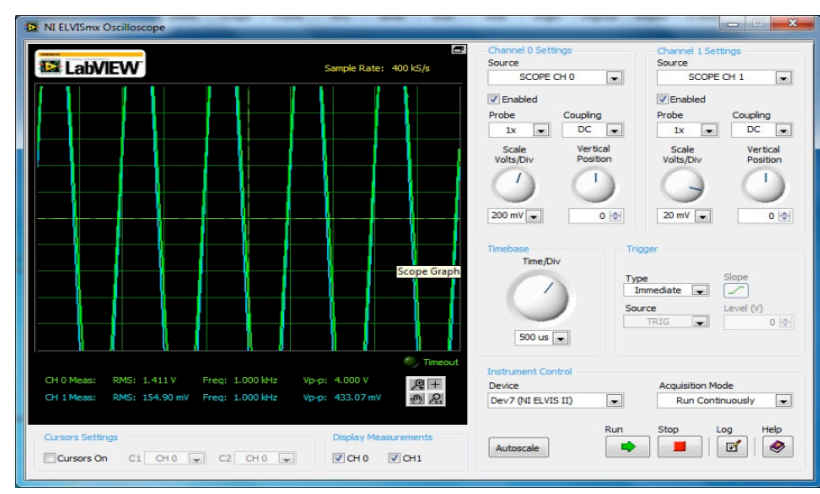

Figure 3. WDM Filter Input

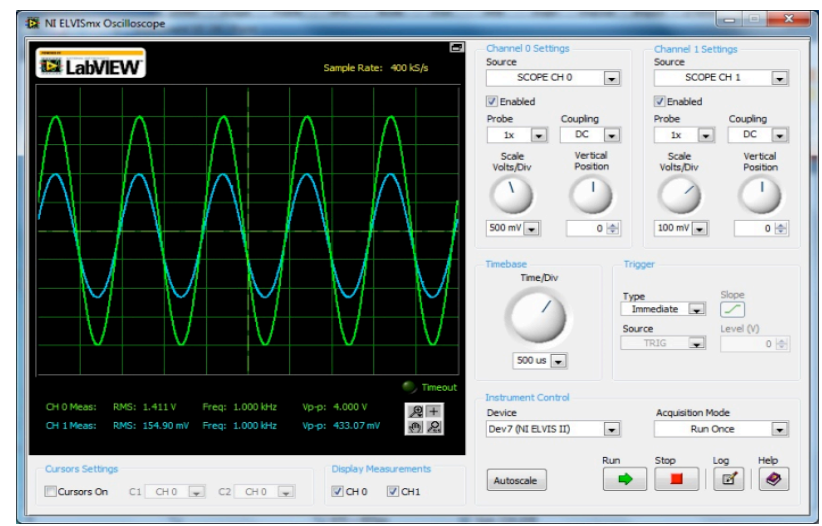

Figure 4. WDM Filter Output

VI. STUDENTS EXPERIENCE USING THE FOTEX TRAINER IN A HANDS ON ENVIROMENT

Two surveys were conducted to get students feedback about the use of the FOTEx and DATEx communication trainers' set-ups in the lab. The survey results for using the DATEx trainer set-up are given in [1]. The following questions about students experience in using the FOTExELVIS II set up in a fiber Optic Communications course were used for the survey:

1- Do you feel comfortable using the FOTEx-ELVIS setup?

2- Where the FOTEx -ELVIS setup experiments clearly written?

3- Where the FOTEx -ELVIS setup experiments procedures easy to follow?

4- Did the use of the FOTEx -ELVIS setup increase your interest in the labs?

5- Did you have difficulties in configuring the FOTEx ELVIS setup software?

6- Did you have difficulties in configuring the FOTEx ELVIS setup hardware?

7- Did you experience difficulties in performing any Fiber Optic Communications experiment?

8- Was the FOTEx -ELVIS lab setup very valuable in terms of learning?

9- Overall, do you support the use of the FOTEx ELVIS setup in this course?

The survey included 15 students enrolled in a graduate fiber optic communications engineering course, and the results of the survey are illustrated in Figure 5 where the blue (light) bar represents a "YES" answer and the red (dark) bar represent a "NO" answer. The X-axis represents

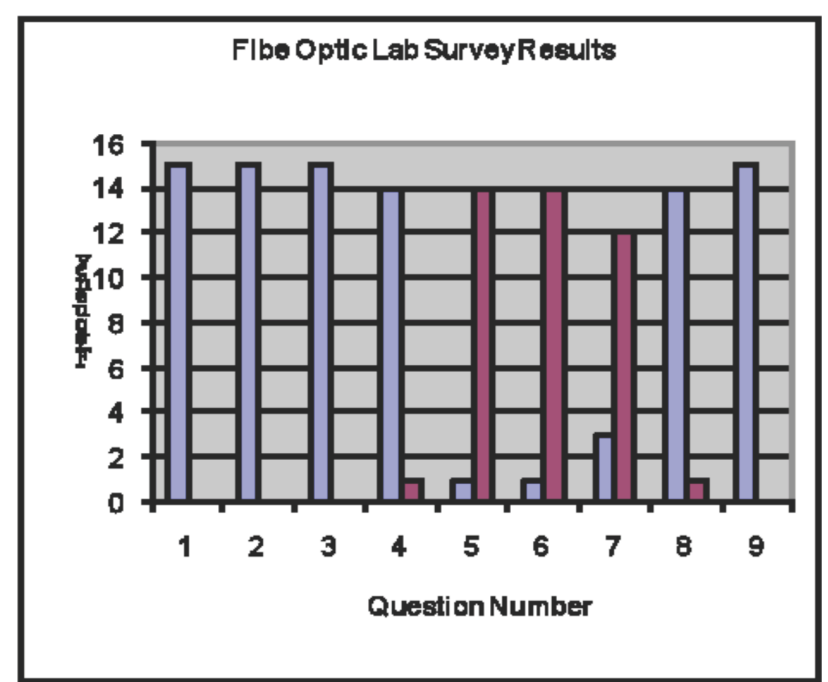

Figure 5. Fiber Optic Communications Survey Results

the question number, and the Y-axis represents the frequency of each answer. As given in the graph, there is a total agreement among all students that they feel comfortable using the FOTEx-ELVIS setup an that FOTEx ELVIS setup experiments clearly written.

The results given in figure 3 shows that there is a total agreement among all students that they feel comfortable using the FOTEx-ELVIS setup an that FOTEx -ELVIS setup experiments clearly written. Also, all students surveyed support the use of the FOTEx -ELVIS setup.

\section{CONCLUSION}

In this work, we presented a plan for remote laboratory collaboration in engineering communications courses. This plan has presented strategies that can be followed and sample set-ups that can be used when implementing remote communications laboratories.

The results of the survey conducted about the use of the fiber optic communications set-up in the lab were very positive, and it shows that the FOTEx-ELVIS II set-up is a user friendly that has a fast learning curve. The next step is to implement the use of this set up with an optical switch matrix and use the set-up in a collaborative distance learning environment.

\section{REFERENCES}

[1] Abu-aisheh, A., Eppes, T, and Al-Zoubi, Abdullah, "Implementations of a Virtual RF and Digital Communications Laboratory for E-Learning". The International Journal of on-line Engineering (IJOE). Spring2010.

[2] Eppes, T. and Schuyler, P., "Pilot Test Results of a New Distance Laboratory Platform" Proceedings of the 2005 Annual Conference \& Exposition, Session 2550.

[3] Cooney, E. \& Shriver, A. "Remote Control of a Robot Using LabVIEW and the World Wide Web", Proceedings of the 2001 ASEE Conference \& Exposition, Session 2526.

[4] Multi-EXPERIMENT Single BoARd Telecoms Trainer FOR THE POPULAR NI ELVIS ${ }^{\mathrm{TM}}$ PLATFORM, EMONA TELECOMS TRAINER ETT-202 http://www.tims.com

[5] 2007, Barry Duncan, Emona Instruments, "Emona DATEx Lab Manual for Electronic Instrumentation Laboratories", 2/e

[6] Abu-aisheh, A. and Farid Farahmand, "LabVIEW-based Integrated Virtual Learning Platform (IVLP)" 10th IEEE International Conference on Advanced Learning Technologies, Sousse, Tunisia, summer 2010 


\section{SPECIAL FOCUS PAPER \\ REMOTE LABORATORY COLLABORATION PLAN IN COMMUNICATIONS ENGINEERING}

\section{AUTHORS}

AKRAM ABU-AISHEH is an Associate Professor of Electrical and Computer Engineering at the University of Hartford where he has served as the assistant chair of the Electrical and Computer Engineering Department and director of the electronic and computer engineering technology program for two years. Professor Abu-aisheh has a doctorate in Optical Communications from the Florida Institute of Technology and Master of Science and Bachelor of Science degrees in Electrical Engineering from the University of Florida. Professor Abu-aisheh has ten years of industry experience in the US including five years as a senior member of the technical staff at Tyco Telecommunications. His research interests include Fiber Optic Communications, Solar Energy, Power Electronics, and Engineering Education. He has published a book, a book chapter, and several international journals and conference papers. Dr. Abu-aisheh may be contacted at abuaisheh@hartford.edu

TOM EPPES received his Ph.D. in Electrical Engineering from the University of Michigan and B.S. and
M.S. degrees from Texas A\&M University. His industry background spans twenty-two years with experience in research \& development, engineering, product development, manufacturing and operations. He was employed by three Fortune 500 companies and later became a principal in four start-up ventures, one of which completed a successful initial public offering. Prof. Eppes has fifteen years of experience in higher education as an assistant professor and associate professor. His research interests include advanced manufacturing technologies, applied photonics, multiphysics modeling, and software development. He is a contributing author for seventy journal and conference papers. In the past seven years, he co-developed six network and software applications now in commercial use. Prof. Eppes served as Chair of the Department of Electrical \& Computer Engineering for three years responsible for six graduate and undergraduate programs. He may be contacted at eppes@hartford.edu.

This article is a modified and extended version of a paper presented at the International Conference EDUCON2012, held April 2012, at University Mohammed V Souissi, Marrakesh, Morocco. Received 27 April 2012. Published as resubmitted by the authors 23 Ocober 2012. 